\title{
In incontinence developing after radical prostatectomy the role of nurses on implementing behavioral therapy
}

\author{
Aylin Aydın Sayılan ${ }^{1}$
}

\begin{abstract}
Developing after radical prostatectomy urinary incontinence (UI) is a major health problem affecting the quality of life of men. Urinary incontinence patients in their care and treatment purpose is to provide continence.

In the treatment of urinary incontinence surgery, medication and behavioral treatments are used. For the purposes of behavioral therapy; increasing the capacity of the bladder function and is aimed at promoting bladder control. Behavioral treatments for incontinence; diet, exercise bladder training and pelvic floor muscle training (PFMT) is located.

Diet is regulated by the bladder diary. PFME is first identified in 1948 by Arnold Kegel, which is aimed pelvic to strengthen the muscles of the base and are expressed in improving the urethral sphincter function. In the literature, in the treatment of incontinence; with drug therapy or surgery, it should be emphasized also behavioral therapy.
\end{abstract}

Keywords: Radical prostatectomy; Urinary incontinence; Behavioral treatments.

\section{Introduction}

According to the recent literature, the prostate cancer, which has been seen in males the middle age history and is still a processing illness. Prostate cancer is the most commonly diagnosed after the lung cancer ranks and it causes so many deaths (WHO 2011, Jemal et al. 2011, Torre and et al. 2015).

There has been a reduction in prostate cancer cases recent times because it has been determined easily by screening tests. Thus prostate cancer treatment can be implemented rapidly which isn't in progress and results of mortality. Mortality ratio is also reduced because of clinical development all around the world and also in our country day by day.

Radical prostatectomy (RP) which is in the treatment of localized prostate cancer in organs, is exceeding life expectancy of 10 years and accepted as gold standard treatment (Sosnowski et al. 2011). Urinary incontinence is a surgical complications after RP. Some researches have reported that ratio of incontinence is between $2 \%$ to $66 \%$ after RP treatment (Kao et al. 2000, Onur \& Orhan 2008). Uriner incontinence is a major health problem in our country and it has performed more commonly after RP (Onur \& Orhan 2008, Gacc et al. 2011).

In the literature, it is a problem which is experienced by patients undergoing radical prostatectomy. The literature emphasizes that behavioral therapy has positive and highlighted effect on this problem (Ballet et al. 2000, Filocamo et al. 2005, MacDonald et al. 2007, Overgård et al. 2008, Ribeiro et al. 2010, Tienforti et al. 2012, Lombraña et al. 2013).

\footnotetext{
${ }^{1}$ Assist. Prof. Dr., Kırklareli University, Faculty of Health Sciences, Nursing Department; aylin.sayilan@,klu.edu.tr
} 
Aydın Sayılan, A. (2016). In incontinence developing after radical prostatectomy the role of nurses on implementing behavioral therapy. Journal of Human Sciences, 13(3), 4644-4649. doi:10.14687/jhs.v13i3.3879

\section{Behavioral Therapy}

1.1 Diet (Level of Evidence 1; Grade of recommendation is A).

Patients who experience incontinence must have diet programmes. Because urinary incontinence affects on excessive fluid intake and it results overactive bladder symptoms which increase incontinence. If fluid intake is insufficient; this situation causes dehydration which can cause constipation and increasing urinary concentrations. If urinary concentration increases, it causes irritation of the bladder mucosa and results to the sense of urgent urination and increase the risk of infection for urinary tract. Some foods and drinks increase diuresis by the way of overactive bladder and cause urge symptoms with excitability.

If foods have spicy, acid or carbon irritant bladder occurs. Caffeinated foods and drinks increase diuresis and they can cause an increasing of the detrusor pressure and excitability of detrusor muscle (Wyman et al., 2009). Alcohol, tomatoes, honey and sugary foods, artificial sweeteners, corn syrup, carbonated soft drinks and fruit, milk and dairy products are other foods that influence the formation of urinary incontinence (Demirci \& Cosar 2009, Ozcan \& Kapucu 2014). Nurses must learn about patients' diets and must assess effects of diets on incontinence. If foods and drinks have negative effect on incontinence patients should be warned.

1.2. Bladder Training (Level of Evidence 1; Grade of recommendation is C).

Bladder training is simple, unexpensive and non-invasive method for people who experience incontinence (Kaplan \& Demirci 2010). Bladder training can be used with other methods like behavioral therapy or drug therapy (Goranitis et al. 2016, Kaplan \& Demirci 2010). This method must be applied up to patients who have physical and mental competence (Demirci \& Coşar 2009).

\subsection{Pelvic Floor Exercise (Level of Evidence 1; Grade of recommendation is C).}

Pelvic floor muscle training (PFMT); is an early effective treatment after radical prostatectomy. It doesn't have side-effects and it is an important method for older patients (Hunter et al. 2004). The aim of this training exercise increased activity of the bladder's capacity and to regain bladder control. This method of treatment can be easily used by health care professionals and PFME is simple inexpensive and effective method (Ozcan \& Kapucu 2014) but instructor must give patients motivation (Berzuk \& Shay 2015).

Nurses have two main responsibilities in the application:

- to prevent the progress of urinary incontinence

- to support patients.

Urinary incontinence as a treatment method was in 1948 firstly described by Arnold Kegel. This method thole to internal pressure increased strength of the abdominal muscle volume and contraction.

PFME helps to tight of the pelvic floor muscles and it affects on lower urinary tract muscles during exercise. Patients must do this exercise properly. In consequence of this training muscle contractions affect pelvic floor muscle tone, anal and urethral sphincter tone increasingly, thus patients don't experience urinary incontinence. Pelvic floor muscle exercises are usually do in the form of 5-10 seconds contraction - relaxation with equal intervals. Hypertrophy development in muscles with slow progress, it takes a long training process. Contractions must apply regularly every day. In addition exercise increases muscle strength, bowel control, orgasm and it reduced sexual problems (Kirschnerhermanns \& Anding 2014). Pelvic floor exercises are repetitive and levator ani muscle with the Pubococcygeus and provided selective voluntary contraction and relaxation of the pelvic muscles thus increase in power. In literarure, pelvic floor muscle exercise apply with electrical stimulation after post prostatectomy, results indicated urinary incontinence decrease on control patients in first month (Parker 2008). Exercise is 
Aydın Sayılan, A. (2016). In incontinence developing after radical prostatectomy the role of nurses on implementing behavioral therapy. Journal of Human Sciences, 13(3), 4644-4649. doi:10.14687/jhs.v13i3.3879

effective in selected patients with early term and conservative management should be recommend in patients with continence. (Sar \& Khorshid 2009). Exercises must consider by physician as a first option for treatment (Yildiran Sarıc1 2009). Because it hasn't side effect and it is useful for stress and mixed type incontinence. Treatment of stress urinary incontinence in recently times, exercise treatment recognize as the first choice (Campbell et al. 2012). Kegel (1949) applied exercise training programme during 14 weeks and reported that stress incontinence decreased all patients. (Parker 2008). In surveys conducted in recent years, stress urinary incontinence is efficacy of pelvic floor muscle exercises have been confirmed (Anderson et al. 2015, Mungovan et al. 2014). Most of the studies have given short-term results (MacDonald et al. 2007, Goode et al. 2011). In the long term results of researches has a significant proportion of patients but they haven't demonstrated symptoms of continence. (Ribeiro et al. 2010, Mariotti et al. 2009). Patients must choose comfortable clothes and must be relax before exercise. When exercise training start patient's bladder must be empty. When patients position ise flexion, abdomen, buttocks and thigh muscles should be relaxed (Parker 2008). Teaching methods of exercise are extremely important. These methods include:

- Stop Test: It uses only for stress urinary incontinence. On the second day micturition, during the mid-stream, forecastle pelvic floor muscles and voluntarily stop the flow of urine. If the patient stops urine quickly, muscle strength is so good. Bladder must be empty, because it creates the risk of infection in this exercise. When patients learn exercise method they must have motivation and apply this programme once a week in first weeks.

Hands should be placed in the abdomen and it should feel the contraction of the abdominal muscles during the contraction and relaxation. Patient should resume the normal breathing while pelvic floor muscles contract. When the without relaxation, it becomes generalized muscle tone in the pelvis. Patients need to be fully concentrate and each contraction should allocate only one fraction during exercise. Patients must relax every 10 seconds after contraction. Each contraction should be provide maximal effort and each contraction begins to be tight. When contraction done completely patients start a new contraction. If patients learn the pelvic floor muscles exercise correctly they can be combination with exercise and daily activities by different positions. Exercise can be done different situations like sitting, watching television, waiting for the bus, talking on the phone. Coughing, sneezing, laughing increases intra-abdominal pressure therefore nurses must give comprehensive information for the patients. Exercise programmes should monitor on a regular basis and continue (Patel et al. 2013). The physiological effects of exercise begins to two weeks later and decreases in complains after 6-8 weeks (Sar \& Khorshid 2009), recovery is seen after 6 months, (Kirages et al. 2003, Dubbelman et al. 2010). Some authors argued that is electrical stimulation therapy with the Kegel exercise necessary? (Bortolami et al. 2015); but this question hasn't efficacy evidence therefore isn't fully clarified (Campbell et al. 2012). This conservative treatment is useful for women (Groenendijk et al. 2008) and children (Kang et al. 2007); but there has'nt sufficient evidence for patients who experienced incontinence after radical prostatectomy (Nyarang of-Dix et al. 2010, Campbell et al. 2012).

Pelvic floor muscle structure is important to maintain continence and sexual health. Pelvic floor exercises are quite effective to improve muscle strength. Behavioral treatment options should be consider for prevention and treatment of urinary incontinence. Nurses must suggest training programme every patient. This programme should include 3-4 times per week for 15-20 weeks (Dumoulin \& Hay-Smith 2010). Each of pelvic floor muscle contraction must during 6-8 seconds and 8-12 times it should be slowly and susceptible to contain three phases (Laycock \& Haslam 2002, Cangöl et al. 2013). Kegel exercises programme should apply by nurses who have certified and they assess the prevalence of urinary incontinence (Ozcan \& Kapucu 2014). A successful exercise program must have enough effort and enough time (Laycock \& Haslam 2002). Nurses must give answers to questions and explain PFME's instruction. 
Aydın Sayılan, A. (2016). In incontinence developing after radical prostatectomy the role of nurses on implementing behavioral therapy. Journal of Human Sciences, 13(3), 4644-4649. doi:10.14687/jhs.v13i3.3879

\section{Conclusion}

Urinary incontinence, which occurs after radical prostatectomy, is a serious health problem that has a great effect on quality of life. It is stated that behavioral therapies has an effect of therapeutic and increase in quality of life for reducing this problem. It is seen that doing behavioral therapy regularly prevents urinary incontinence, increases conscious about pelvic floor and also life satisfaction and decreases the problems. Multidisciplinary teamwork is necessary to apply behavioral therapy regularly and also to encourage individuals. Due to their educative and advisor roles, nurses play great role in counseling and teaching practises.

\section{References}

Anderson, C., Omar, M. I., Campbell, S. E., Hunter, K. F., Cody, J. D., \& Glazen, C. M. (2015). Conservative management for postprostatectomy urinary incontinence. Cochrane Database Systematic Rev., 1: CD001843. doi: 10.1002/14651858.CD001843.pub5.

Aksaç, B., Aki, S., Karan, A., Yalçın, Ö., Işı1koğlu, M., \& Eskiyurt, N. (2003). Biofeedback and pelvic floor exercises for the rehabilitation of urinary stress incontinence. Gynecologic and obstetric investigation, 56(1):23-7.

Ballet, G. T., Gerber, G. S., Minor, T. X., Mhoo, D., McFarland, J., Kim, H. L., \& Brendler, C. B. (2000). Effect of preoperative biofeedback / pelvic floor training on continence in men undergoing radical prostatectomy. Urology, 56(4):627-30.

Berzuk, K., \& Shay, B. (2015). Effect of increasing awareness of pelvic floor muscle function on pelvic floor dysfunction: a randomized controlled trial. International Urogynecology Journal, 26(6):837-44.

Bortolami, A., Vant, C., Banchelli, F., Guccione, A. A., \& the Pillastr, P. (2015). Relationship between female pelvic floor dysfunction and sexual dysfunction: an observational study. The Journal of Sexual Medicine, 12(5):1233-41.

Campbell, S. E., Glazen, C. M., Hunter, K. F., Cody, J. D., \& Moore, K. N. (2012). Conservative management for postprostatectomy urinary incontinence. Cochrane Database Systematic Rev.,1: CD001843. doi: 10.1002/14651858.CD001843.pub4.

Cangöl, E., Aslan, E., \& Yalçın, Ö. (2013). Pelvic Floor Muscle Exercises forWomen and the Nurse's Role. Journal of Education and Research in Nursing, 10(3):49-56.

Demirci, N., \& Coşar, F. (2009). Behavioral Treatment of Urinary Incontinence Therapy. Suleyman Demirel University Medical School Journal, 16(3):35-40.

Dubbelman, Y., Groen, J., Wildhage, M., Rikka, B., \& Bosch, R. (2010). The recovery of urinary continence after radical retropubic prostate in a randomized trial Comparing the effect of physiotherapist-guided pelvic floor muscle exercises with guidance by an instruction folder only. BJU International, 106(4):515-22.

Dumoulin, C., \& Hay-Smith, J. (2010). Pelvic floor muscle training versus no treatment, or inactive control treatments, for urinary incontinence in women. The Cocbrane Collaboration, $1: 1-52$.

Filocamo, M. T., Li, Marzi, V., del Popolo, G., Cecconi, F., Marzocco, M., Tosto, A., \& Nicita, G. (2005). Effectiveness of early pelvic floor rehabilitation treatment for post-prostatectomy incontinence. European Urology, 48(5):734-8.

Gacc, M., Carini, M., Simonato, A., Imbimbo, C., Gontero, P., Briganti, A., De Cobelli, O., Fulcoli, V., Martorana, G., Nicita, G., Mirone, V., \& Carmignani, G. (2011). Factors Predicting continence recovery 1 month after radical prostate in Multicenter results of a survey. International Journal of Urology, 18(10):700-8.

Goode, P., Burgio, K. L., Johnson, T. M., Clay, O. J., Roth, D. L., Markland, A. D., Burkhardt, J. H., Issa, M. M., \& Lloyd, L. K. (2011). Behavioral therapy with or without biofeedback and pelvic floor electrical stimulation for persistent postprostatectomy incontinence: a randomized controlled trial. JAMA, 305(2):151-9. 
Aydın Sayılan, A. (2016). In incontinence developing after radical prostatectomy the role of nurses on implementing behavioral therapy. Journal of Human Sciences, 13(3), 4644-4649. doi:10.14687/jhs.v13i3.3879

Goranitis, I., Barton, P., Middleton, L. J., Deeks, J. J., Daniels, J. P., Latthe, P., Coomarasamy, A., Rachaneni, S., McCooty, S., Verghese, T. S., \& Roberts, T. E. (2016). Testing and Treating Women after Unsuccessful Conservative Treatments for Overactive Bladder or Mixed Urinary Incontinence: A Model-Based Economic Evaluation Based on the BUS Study. PLoS One, 11(8):e0160351.

Groenendijk, P. M., Halilovic, M., Chandi, D. D., Heesakkers, J. P., Voorham-Van Der Zalm, P. J., \& Lycklama Anijeholt, A. A. (2008). Extracorporeal magnetic innervation therapy: Assessment of clinical efficacy in relation to Urodynamic parameters. Scandinavian Journal of Urology and Nephrology, 42(5):433-436.

Hunter, K. F., Moore, K. N., Cody, D., \& Glazen, C. M. (2004). Conservative management for postprostatectomy urinary incontinence. Cochrane Database Systematic Review, (2): CD001843.

Jemal, A., Siegel, R., Xu, J., \& Ward, E. (2011). Cancer statistics. CA: A Cancer Journal of Clinicians, 61(2):133-4.

Kang, S. H., Bae, J., Shim, K., Park, H. S., Cheon, J., \& Lee, J. G. (2007). Extracorporeal magnetic innervation therapy in children with nocturnal enuresis refractory monosymptomatic. Urology, 70(3): 576-580.

Kao, T. C., Cruess, D. F., Garner, D., Foley, J., Seayr, T., Friedrichs, P., Thrasher, J. B., Mooneyhan, R. D., McLeod, D. G., \& Moul, J. W. (2000). Multicenter patient selfreporting questionnaire on impotence, incontinence and stricture after radical prostatectomy. Journal of Urology, 163(3):858-864.

Kaplan, S., Demirci, N. (2010). Conservative Treatment Methods Urinary Incontinence. Firat Health Service Journal, 5 (13):1-14.

Kırages, D., Parekh, A. R., Feng, M. I., Bremer, H., Kaswick, J., \& Aboseif, S. (2003). The role of pelvic floor exercises on the post-prostatectomy incontinence. Journal of Urology, 170 (1):130-3.

Kirschner-Hermanns, R., \& Anding, R. (2014). Conservative treatment of male urinary incontinence. Der Urologe, 53(3):333-4, 336, 338.

Laycock, J., \& Haslam, J. (2002). Pelvic floor muscle exercise in the treatment of urinary incontinence. Therapeutic management of incontinence and pelvic pain pelvic organs Disorders. London: Springer-Verlag, p.63-72.

Lombraña, M., Izquierdo, L., Gómez, A., \& Alcaraz, A. (2013). Impact of a nurse-run clinic on prevalence of urinary incontinence in men undergoing radical prostatectomy and everyday life. J. Wound Ostomy Continence Nursing, 40(3):309-12.

MacDonald, R., Fink, H. A., Huckabay, C., Monge, M., \& Wilt, T. (2007). Pelvic floor muscle training to improve urinary incontinence after radical prostate in a systematic review of effectiveness. BJU International, 100 (1): 76-81.

Mariotti, G., Sciarra, A., Gentilucc, A., Salcicci, S., Alfaro to, A., Di Pierro, G., \& Gentile, V. (2009). Early recovery of urinary continence after radical prostatectomy using early treatment-associated pelvic floor electrical stimulation and biofeedback. Journal of Urology, 181(4):1788-93.

Mungovan, S. F., Huijbers, B. P., Hirschhorn, A. D., \& Patel, M. I. (2014). What makes me the leak? The investigation of objective and self-report measures of early urinary incontinence after radical prostatectomy. Neurourology and Urodynamics, 35(2):225-9.

Nyarang of-Dix, J. N., Schultz-Lampel, D., Hohenfelln, U., Huber, J., Hatiboğlu, G., Djakovic, N., Haferkamp, A., \& Hohenfellner, M. (2010). Conservative management of postoperative urinary incontinence in men. Der Urologe, 49(4):498-503.

Onur, R., \& Orhan, I. (2008). After Radical Prostatectomy Incontinence Resulting Pathogenesis and Current Treatment Approaches. Firat Medical Journal, 13(2):80-87. 
Aydin Saylan, A. (2016). In incontinence developing after radical prostatectomy the role of nurses on implementing behavioral therapy. Journal of Human Sciences, 13(3), 4644-4649. doi:10.14687/jhs.v13i3.3879

Overgård, M., Angels, A., Lydersen, S., \& Mørkved, S. (2008). Does physiotherapist-guided pelvic floor muscle training reduce urinary incontinence after radical prostatectomy? A randomized controlled trial. European Urology, 54 (2):438-48.

Ozcan, M., \& Kapucu, S. (2014). Urinary Incontinence Nursing Approach to Emerging geriatric patient. Nursing Journal of Hacettepe University Faculty, 1(2):101-109.

Patel, M. I., Yao, J., Andrew, D., Hirschhorn, A. D., \& Mungovan, S. F. (2013). Preoperative pelvic floor physiotherapy after radical retropubic prostatectomy Improves continence. International Journal of Urology, 20(10):986-92.

Parker, M. (2008). Stress Urinary Incontinence Mixed Incontinence and in women functional with electrical stimulation and biofeedback with a single press together the user event. T. C. Obstetric Department of Health and childrendiseases Training and Research Hospital of Obstetrics and Gynecology Thesis.

Ribeiro, L. H., Prota, C., Gomes, C.M., de Bessa, J.Jr., Boldarine, M.P., Dall'Oglio, M.F., Bruschini, H., \& Srougi, M. (2010). Long-term effect of early postoperative pelvic floor biofeedback on continence in men undergoing radical prostate in a prospective, randomized, controlled trial. Journal of Urology, 184(3):1034-9.

Sar, D., \& Khorshid, L. (2009). The effects of pelvic floor muscle training on stress and mixed urinary incontinence and quality of life. Wound Ostomy Continence Nursing Journal, 36(4): $429-35$.

Sosnowski, R., Szymanski, M., Wolski, J. K., Nadolski, T., Kalinowski, T., Demkow, T., Peczkowski, P., Pilichowska, M., Ligaj, M., \& Michalski, W. (2011). Urinary incontinence after radical prostatectomy - experience of the last 100 cases. Central European Journal of Urology, 64(4): 213-7.

Tienforti, D., Sacco, E., Marangu, F., D'addess, A., Racioppi, M., Gulino, G., Pinto, F., Totaro, A., D'Agostino, D., \& Bassi, P. (2012). Efficacy of an assisted, low-intensity programmer of perioperative pelvic floor muscle training in improving the recovery of continence after radical prostate in a randomized controlled trial. BJU, 110(7):1004-10.

Torre, L., Bray, F., Siegel, R., Ferlay, J., Lortet-Tieulent, J., \& Jemal, A. (2015). Global cancer statistics, Cancer statistics. CA: A Cancer Journal of Clinicians, 65(2):87-108.

WHO (2011). Cancer incidence and mortality worldwide: Lyon, International Agency for Research on Cancer, 2011 (IARC CancerBase No.10). http://www.who.int/nmh/publications/ncd_report_chapter1.pdf?ua=1.E.T. 10.09.2016

Wyman, J. F., Burgio, K. L., \& Newman, D. K. (2009). Practical aspects of lifestyle Modifications and Behavioural Interventions in the treatment of overactive bladder and urgency urinary incontinence. Internationa Journal of Clinical Practice, 63(8):1122-3.

Yildiran Sarıc1, D. (2009). Urinary Incontinence Treatment of Pelvic Floor Exercises Biofeedback Neuromodulation-Home Exercise Training Implementation For Short-Term Results. T. C. Istanbul Education and Research Hospital. Obstetrics and Gynecology Thesis. 